\title{
Data Monitoring and Evaluation of Renewable Energy Systems, in Particular Energy Storage Systems, and Definition of Categories of Simi- lar Use
}

\author{
Adolfo Perujo, Rudi Kaiser, Dirk-Uwe Sauer, Heinz Wenzl, Ian Baring-Gould, Nigel Wilmot, Flor- \\ ence Mattera, Stathis Tselepis, Frans Nieuwenhout, Carlos Rodrigues, Alan Ruddell, Per Lundsager \\ and Vojtech Svoboda
}

\begin{abstract}
This paper describes a general method on how to monitor renewable energy systems (RES) and evaluate the data in such a way that the operating conditions and performance of individual components and the system as a whole can be analysed and compared. The enormous variation between RES, which is the result of user requirements and local climatic conditions, makes it necessary to classify different installations into categories of similar use. Only installations belonging to the same category of use can be compared in a meaningful manner. First results in the development of a similarity index and in identifying and describing categories of similar use are presented. The project results will make it possible to match any installation to a category which resembles its operating conditions most closely.
\end{abstract}

Index Terms - Batteries, Energy storage, Measurement, Modelling, Photovoltaic power systems, Power system monitoring.

\section{INTRODUCTION}

$\mathrm{R}$ ENEWABLE energy systems (RES) are unique among energy supply systems because their performance and design depends entirely on the location and climatic conditions. A system optimised for an application in one location may be inadequate in another location even if the application and user

The main financial support of this project is from The European Union under the contract ENK6-CT2001-80576. In addition, the support of the governments of the United States-of America and Australia as well as other public and private support is acknowledged.

A. Perujo is with the Joint Research Center- Institute for Environment and Sustainability - Renewable Energies Unit (ISPRA), Italy

R. Kaiser and D. U. Sauer are with the Fraunhofer-Institute for Solar Energy Systems ISE, Germany.

H. W.enzl is with the Beratung für Batterien und Energietechnik, Germany

I. Baring-Gould is with the National Renewable Energy Laboratory, USA

N. Wilmot is with the Australian Cooperative Research Centre for Renewable Energy, Australia

F. Mattera is with the Commissariat a l'Energie Atomique - Groupement Energetique de Cadarache, France

S. Tselepis is with the Centre for Renewable Energy Systems, Greece

F. Nieuwenhout is with Energy Research Centre of the Netherlands

C. Rodrigues is with the National Institute for Engineering and Industrial Technology, Portugal

A. Ruddell is with the Energy Research Unit (ERU) at Rutherford Appleton Laboratory, UK

P. Lundsager is with the Risoe National Laboratory, Denmark

V. Svoboda is with the Centre for Solar Energy and Hydrogen Research, Germany. requirements are identical.

Batteries in a number of RES in Central Europe have been investigated using among other methods a calculation of the yearly variation of state-of-charge and their operating conditions have been grouped into four categories [1], [2]. It is obvious even using only this time series that the operating conditions of batteries differ greatly. Without knowledge of the operating conditions it is difficult to select the most appropriate battery and compare systems performance.

Data acquisition systems (DAS) can demand a significant share of the total investment. It is therefore necessary to plan carefully what should be measured and how the data will be evaluated to meet the needs of the user, the systems operator and/or systems owner.

\section{SPECIFICATION OF Minimal REQUiREMENTS OF} MEASUREMENT PROCEDURES

To satisfy the needs of the monitoring process, five essential functions must be considered:

- Measurement of physical magnitudes that will indicate the system condition and operating status,

- Processing of the measurements to generate data displaying the installation condition and operating status as needed by the design methodology,

- Storage of data relevant to the system in an accessible format,

- Understanding and documentation of the power system to address any data concerns,

- Provision so that the monitoring system should continue to provide information on appropriate parameters even if the power system is not operating.

The position of the sensor in the circuit, e.g. measurement of PV current before or after the solar controller, the accuracy of the sensor, the averaging processes employed, etc. need to be considered in order to provide the maximum information possible within a given budget constraint. It is for instance recommended to calculate separate averages for the battery current, one giving the average current and Ah into the battery in a given period, the other giving the average current and Ah out of the battery. Without any additional hardware cost and 
negligible additional cost for data storage the real energy throughput of the battery can then be measured. Fig. 1 shows the points of measurements for a general systems layout with a DC bus. Similarly a system layout with an AC bus is also defined. A full specification will be available on www.benchmarking.eu.org

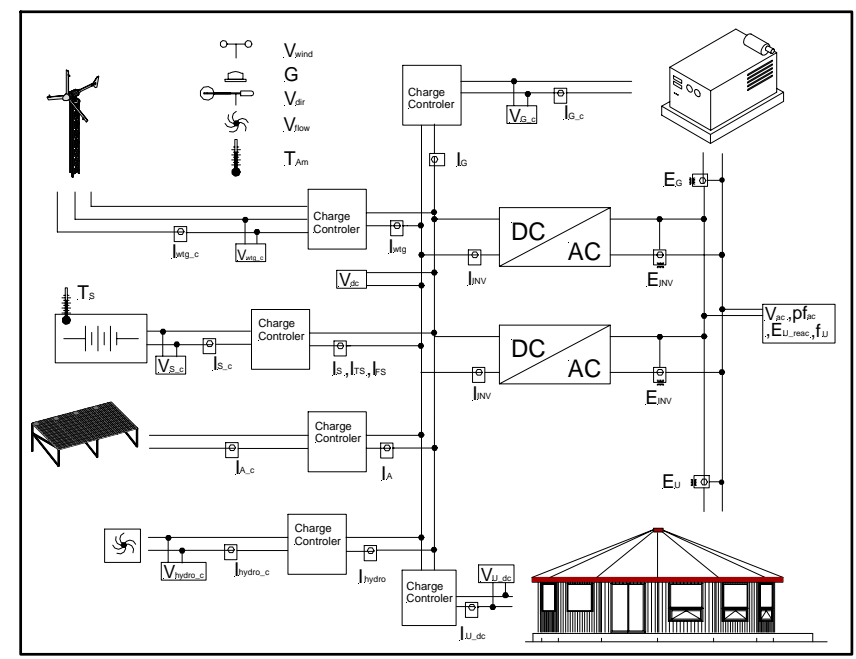

Fig. 1 Schematic of a DC based power system

Three levels of data collection are suggested for system monitoring:

1. General performance monitoring to measure the output performance of the power system. Based mainly on system inputs and outputs, not on the internal working of the power system. This type of monitoring system would be used to ensure that the power system is operating, power is being supplied within proper parameters and that specific components are in fact operational.

2. System performance monitoring. It is similar to the above level but includes internal power system measurements. This level of monitoring can be used to assess component performance on a macro level and assist in trouble shooting of system components.

3. Scientific monitoring used to obtain an understanding of system operation and real time power flow. Data is also collected to monitor component efficiency and determine very specific operating performance.

Power measurements of items connected to the DC bus are completed by measuring the current between the DC bus and the device while taking simultaneous voltage measurement of the link. AC devices are measured through dedicated power (kVA, kW and/or Power Factor) measurement using transducers designed for these activities. In cases where more than one component of the same type is included within the power system, such as two strings of batteries or two power converters, the measurements can either be taken independently or as a summation of the two components.

Due to the prevalence of distinct charge controllers or sig- nal conditioners between a specific component and the connection to other devices, i.e. AC or DC bus, two parameters must be measured, one at the component and one at the specific bus. If such a device does not exist, or is not to be considered, these measurements do not need to be made and the voltage at the component can be taken as the same as the voltage on the specific bus.

\section{A. Signal Collection and Recording}

Data collection can be broken down into two time intervals, the first is the measurement interval while the second is the storage interval. The measurement interval represents how often a sensor is used to record the value or condition it was designed to sense, such as voltage on the DC bus or wind speed. These measurements occur quite frequently and in most remote systems it would be impossible to record all of this information over a long period. To reduce the amount of data, measurements are usually processed to provide a meaningful average value over a longer time period, usually between minutes and days. This is the recording interval. The measurements are being continuously made and forgotten, but the important information is recorded in the data logger memory for future use.

The sensor measurements account for the majority of data collection complexity. Initially it is important to understand the dynamics of the signals being measured to ensure that the information being collected is valid, meaning that it represents the phenomenon being measured. It is important that the sample or measurement interval accurately captures the phenomena in questions, such as AC ripple on a DC current. Collection accuracy will depend on the level and type of monitoring that will be required by the system or the desired results.

The level of system monitoring will dictate the requirements for the different time intervals for data storage. Due to the different uses of the data, data storage should be conducted at different gradations.

General performance monitoring. Generally measurements are assumed to be stored at large intervals and with limited number of parameters to outline basic system operation. In many cases daily averages of operational totals are enough to provide accurate assessment of system operation. Data for performance monitoring is typically stored as daily summary values with maximum and/or minimum values as needed.

System performance monitoring. Due to the number of parameters being measured and the length of time of system operation, hourly averaged or summed parameters will be sufficient to allow monitoring of the system performance and assessment of the operation of different components.

Scientific monitoring. Data collection and storage rates will depend on the level of testing to be conducted. In many cases data is stored every minute. 
III. STANDARD EVALUATION REPORT AND CLASSIFICATION OF SySTEMS INTO CATEGORIES OF SIMILAR USE.

A comparison between different systems requires a data analysis in a standardised manner. Different terminology and different representations of the same data make it difficult, if not impossible, to compare data from different locations with potentially different applications. For this reason, a stringent, formalised manner of presenting data is suggested. Graphs, histograms and performance figures can then be used to identify categories of similar use of components, e.g. batteries, fuel operated generators or any other component in RES. Examples of possible categories with similar component sizes and overall energy throughput but completely different requirements are:

1. "Large solar installation with possibly commercial usage aspects”. PV + battery + wind (in some cases) + backup generator. Solar fraction in the range of $50 \%$; high currents, significant daily energy throughput (0.5 1 times nominal capacity), professional operation

2. "Battery for smoothing". Wind + diesel + battery. The, battery is used to reduce the number of diesel start-ups, battery storage time $\sim 30$ minute or less with high discharge/charge rate and possibly very high-energy throughput.

A standard evaluation report may contain more than 10 time series, histograms and many more performance indicators. The task of matching data of a given installation to any other therefore represents a multidimensional vector analysis with weighted dimensions.

\section{A. Performance Index}

In order to be able to easily compare different RES systems, it is important to produce normalised performance indicators. The following definitions are made:

- The battery capacity is given at its 10 hourly rate C10.

- The battery voltage is normalised to the cell voltage, i.e. battery voltage divided by the number of cells in the battery pack.

- The charge and discharge current is normalised to the C10 rate of the battery.

- The relevant energy balances are normalised to the nominal power Po, thus, resulting in final yields. (For the specific case of PV installations dividing the relevant energy balance by the total array area and total inplane irradiance will result in overall efficiencies).

The above normalised energy throughputs will provide overall energy balances for the system. These energy balances include energy imported from or exported to the grid, or from an auxiliary generator (genset), and indicate the contribution that the RES generator (e.g. PV array) has made to the overall operation of the system.

The key parameters of interest which result from the system energy balance are:

1. Total input energy: it is the total input energy to the system coming from the RES generator, the genset (back-up generator), and the grid.
2. RES generator fraction: this corresponds to the energy supplied by the renewable generators to either the energy storage or the loads (i.e. surplus energy that can neither be stored or used and has to be dissipated is not included) as a percentage of total energy demand. (In a PV system, this is the solar fraction, i.e. energy supplied by solar as percentage of total energy demand.)

3. Net energy drawn from the storage system (batteries, etc.).

4. Net energy supplied to the storage system.

The mean values of these parameters over the reporting period give a good indication of the overall performance of RES systems, whether operating in stand-alone, hybrid generator or grid connected modes.

Furthermore, the determination of mean operating efficiencies for each component will be possible by using separate energy balance data over the reporting period for each of the different Balance of System (BOS) components calculated by summing the energy flow in and out of the components.

\section{B. Visualisation of results: graphical presentation}

Besides tables containing general information, climatic data, system balance and performance indexes as defined above, graphical representations in the form of plots are important to illustrate the operation of a RE system. However, not all graphs are suited for proper presentation of data in a manner that is both easy to understand and serves specific purposes. The following graphs are included in the SER report:

1. A bar graph plotting the data availability in \% for each month of the reporting period (one year) as well as for the year

2. The normalised hourly mean PV array output power plotted in a scatter diagram versus hourly in-plane irradiance in $\mathrm{kW} / \mathrm{m}^{2}$. This graph indicates how consistently the PV plant operates near to its maximum capacity. It also reveals any anomalous data points that should then be further investigated.

3. The 10-min average wind turbine output power $(\mathrm{kW})$ plotted in a scatter diagram versus 10 -minute average wind speed $(\mathrm{m} / \mathrm{s})$ measured at hub height. This graph will indicate the effective power curve of the WT(s) determined by a binning of the data points using $1 \mathrm{~m} / \mathrm{s}$ bin width.

4. A bar graph showing daily array and reference yields superimposed for each day of the month in case of monthly reports, or a bar graph showing monthly array and reference yields superimposed for each month in case of six-monthly or yearly summaries.

5. A similar bar chart as in point 4 is included for wind turbines. For wind turbines the relevant measurement is the measured power output and the corresponding $\mathrm{c}_{\mathrm{P}}$ factor (efficiency) based on measured wind speeds.

6. A bar graph representing the monthly average electricity generation and load for micro-hydro generators.

7. Graphs representing:

- the maximum and minimum battery voltage per day (bar chart),

IEEE PowerTech Conference 2003, Bologna, Italy, June 23-26, 2003. 
- battery current $\left[\mathrm{I}_{10}\right]$ versus mean cell voltage [V],

- operation time in \% of the year at a given SOC [\%],

- time series of the state of charge through the year

- operation time in \% of the year at a given mean cell voltage [V],

- operation time in \% of the year at a given battery current in unit I_10

- charged and discharged Ah in units of battery capacity per month

- charge factor in Ah and Wh per month

- operation time in \% of the year at a given battery temperature

8. Graphs representing inverter efficiency and energy throughput versus input power in units of inverter nominal power.

9. A bar chart representing the load consumption per day of the year.

The above information has to be either provided by the operator of the monitored RES plant or by the proper use of algorithms to extract them from the time series of the RES-plant monitored values. In particular the time series for the State of Charge of the batteries will be obtained by using the program for calculation the state of charge (SOC) developed by Fraunhofer ISE.

The data evaluation tool is currently under development and will be available for the project partners these days. However it is planned within this year to make available the tool for the public. Simply by defining the systems and the data, the Internet tool will analyse the data and will provide the user with a standard evaluation report. This public available tool should become a standard for system analysis and assessment as well as for the benchmarking of components. As mentioned above only a common used and widely accepted procedure for the data analysis will assure a broad acceptance of the results obtained.

\section{CATegorisation Process}

The standard evaluation reports will be used to define RES categories of similar operating conditions. Different categories have distinctly different requirements and operating conditions for at least one major component. Batteries are the key component in RES determining the system life and performance; they also significantly influence the system cost. Therefore the categorisation process will be mainly controlled by the influence of battery ageing in RES.

Fig.2 attempts to show how a large number of standard evaluation reports would be grouped to form a few categories.

The categorisation process to be applied to the different RES applications is based on the so-called "attributes". These attributes are the main ageing/degradation processes identified in lead acid batteries. These are corrosion, irreversible sulfation, active mass structural change, electrolyte stratification, active mass shedding, thermal runaway, extensive gassing and electrolyte freeze. The selection of these attributes is also connected to lifetime prediction models.

Risk indexes are assigned to these attributes (High risk, Medium risk, Minimal risk, No/Neglected risk) by means of pa- rameters benchmarks. These parameters' benchmarks are created on the base of experts' knowledge. The scheme Fig. 3 demonstrates the index assignment process to an attribute. In the first step the relevant parameters concerning the particular attribute will be selected from the SER In the second step the selected parameters will be evaluated by the means of the parameters' benchmark (experts' knowledge) and finally the four level index will be assigned to the attribute. This process will be performed to all seven attributes used in the categorization. Later the assignment process can run fully automatically.

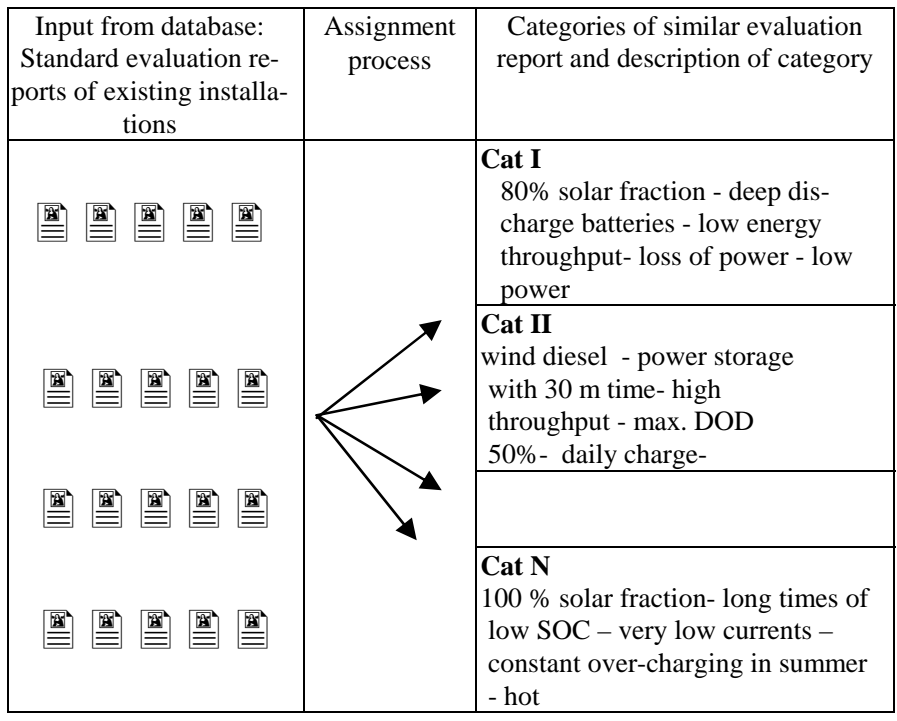

Fig. 2 Categorisation process

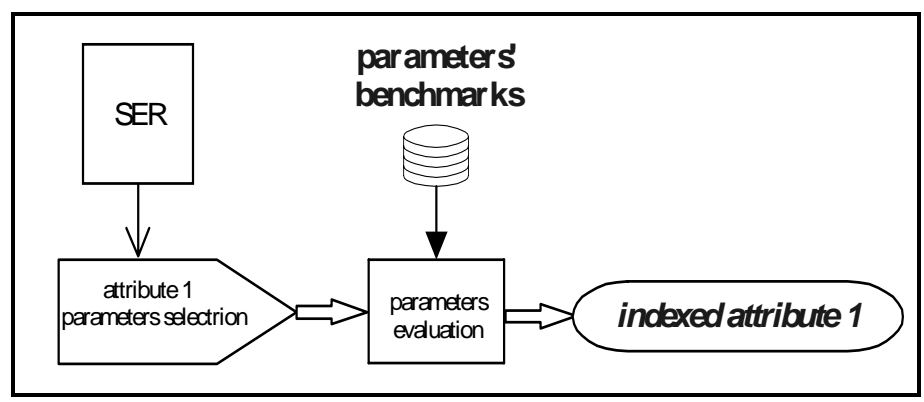

Fig. 3 Schematic demonstration of the index assignment to an attribute.

Then the "indexed attributes" are visualised allowing system class/category determination and fitting of the appropriate components (e.g. batteries) in a radar type chart. Fig. 4 depicts the visualisation of attributes for a particular example of RES system, i.e. a photovoltaic system with a small battery that is frequently undercharged in a cold climate.

\section{CONCLUSIONS AND OUTLOOK}

This project provides information on how RES and their components are currently used and this information is used 
within the ongoing BENCHMARKING project to develop test procedures for benchmarking products. Users will be able to make better decisions based on test results and manufacturers will be able to focus their development better on requirements. The information obtained will help the industry in making better and more cost-effective products.

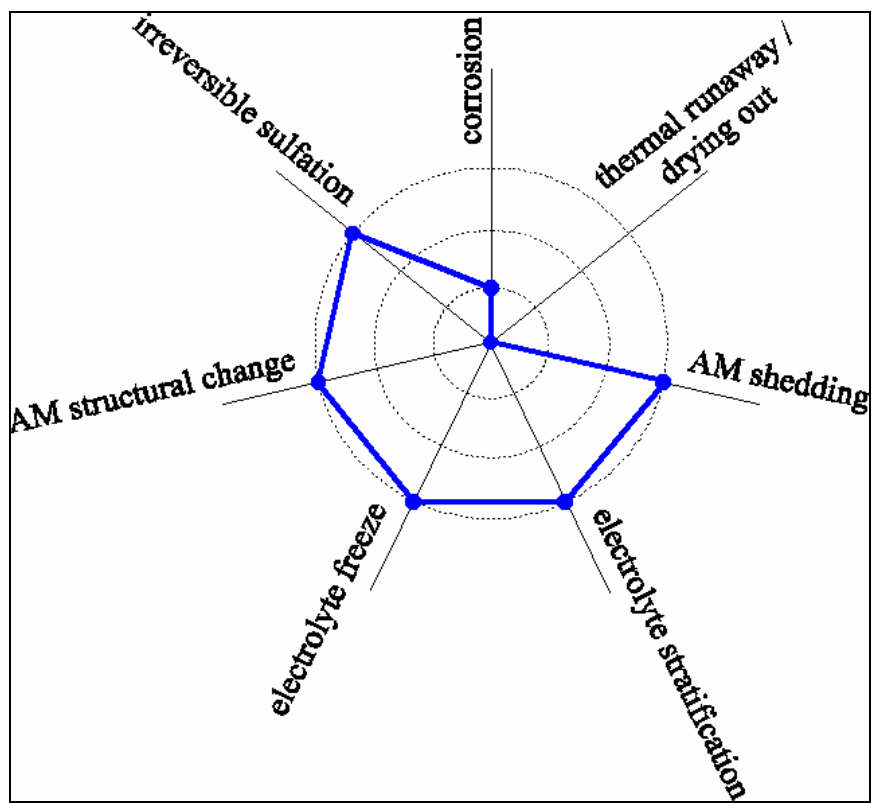

Fig. 4 Radar type chart for a photovoltaic system in a cold climate with a small storage system being frequently undercharged

All industrial companies will be able to benefit from the project results which will be openly accessible. Ultimately the project results have the potential of setting new rules. In a future mature market for components for renewable energy systems, a product should then be clearly labelled as being suitable for a certain category of RES and be able to prove its suitability with results from appropriate tests.

\section{REFERENCES}

[1] D.-U. Sauer, M. Bächler, G. Bopp, W. Höhe, J. Mittermeier, P. Sprau, B. Willer, M. Wollny, "Analysis of the performance parameters of leadacid batteries in photovoltaic systems“, J. Power Sources, 64 (1997) 187-201

[2] D.U Sauer, G. Bopp, M. Bächler, W. Höhe, A. Jossen,, P. Sprau, B. Willer, M. Wollny,"What happens to batteries in PV systems or Do we need one special battery for solar applications ?" in Proc. $14^{\text {th }}$ European Photovoltaic Solar Energy Conference, Barcelona, 1997, pp. 1348-1353

\section{BIOGRAPHIES}

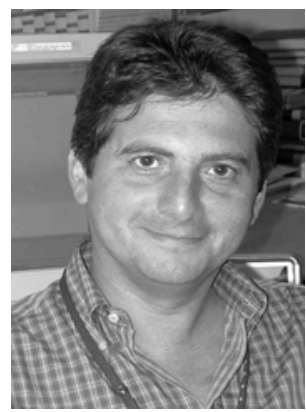

Adolfo Perujo was born in Seville, Spain, on July 23, 1957. He graduated from the Universidad de Sevilla (Spain) and obtained the MSc (Accelerator Physics) in the University of Manitoba (Canada). He completed his $\mathrm{PhD}$ (Applied Physics) at the University of Guelph (Canada).

His employment experience include AECL Chalk River Laboratory (Canada), and at different institutes at the Joint Research Centre (Institute for Reference Material and Measurements, Safety Technology Institute, Advance Material Institute, Environment Institute and Institute for Environment and Sustainability). He has been head of the Hydrogen-Material Interaction Group and since 1989 he is involved in Renewable Energies. At present he is the head of the group dealing with storage technologies and demonstration of Renewable Energy Systems.

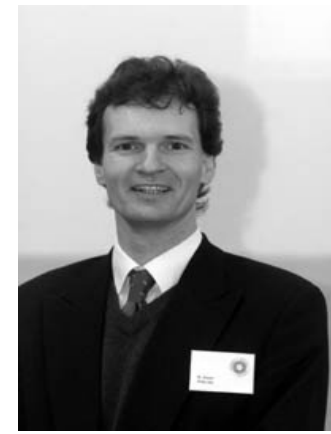

Dirk Uwe Sauer (born in 1969 in Mannheim / Germany) graduated in Physics at the University of Darmstadt in 1994. Today he is the head of the group storage systems and off-grid power supply systems at the Fraunhofer-Institut für Solare Energiesysteme ISE in Freiburg / Germany. His special field of interest are battery system technology and lead-acid battery modelling, technical, social and socio-economic aspects or rural electrification and energy management systems for autonomous power supply systems and distributed generation in grids.

Efstathios Tselepis was born in Athens, Greece on March 24th 1958. In 1982, he received his Bachelor Degree of Science in Physics from Ottawa University in Canada and then in 1988 he received his Doctor's degree in Solid State Physics from Ottawa University in Canada. He worked for 2 years at the National Research Council of Canada in Ottawa, in the field of High Temperature Superconductivity and since 1994 he is working at the Centre for Renewable Energy Sources in Athens, Greece. He has 9 years experience in R\&D projects in Canada and 8 years experience in R\&D projects funded by the E.U., the European Industry and the Greek State. He has participated in 30 research programs (co-ordinator in one of them). His recent work is related with: PV and hybrid system energy management, testing procedures and performance evaluation of systems and devices, evaluation of PV systems economic viability. Definition of test procedures for Electric Vehicles and associated hardware for a simplified monitoring system. In 2002, he received a Patent form the Organisation of Industrial Property, OBI, for the development and realisation of a Simplified Monitoring System, hardware and software.

Frans Nieuwenhout was born in 1957 in the Netherlands and studied Physics and Astronomy at Utrecht University. After working for the Physics and Society unit of this University for a year, he stayed four years in Indonesia for the Ministry of Development Co-operation. Since 1990 he is employed by ECN, where his current work focuses on monitoring and evaluation of small stand alone PV systems, mainly solar home systems in developing countries.

Carlos Rodrigues, was born in Castelo Branco, on September 18,1962. He graduated in 1990 in Geophysical Sciences at the University of Lisbon and Mastered in 1997 in Mechanical Engineering at the Technical University of Lisbon.

He has worked at INETI in solar energy since 1987 and in photovoltaic projects since 1989. On his master theses, he worked at the development of calculation methods for sizing and simulating stand-alone photovoltaic power systems. His main activities have been monitoring of solar systems (thermal and photovoltaic) and computer simulation and operation analysis of photovoltaic systems.

Alan Ruddell (IEE member \& CEng 1992) graduated from Queen's University, Belfast, in Electrical Engineering in 1971, and from Strathclyde University, Glasgow, with a PhD in 1975. His employment history includes periods of research and industrial experience, and since since 1992 he has worked in renewable energy systems research at Imperial College, London, and at Rutherford Appleton Laboratory, near Oxford. His research intersets include energy storage, and wind/photovoltaic stand-alone power systems.

Per Lundsager was born in Aarhus, Denmark, on March 5, 1941. He graduated with a M.Sc. in Mechanical Engineering from the Danish Technical University (DTU) in January 1967. After continued study in structural mechanics at DTU in parallel to his other employments he completed his Ph.D. in solid mechanics in September 1979.

IEEE PowerTech Conference 2003, Bologna, Italy, June 23-26, 2003. 


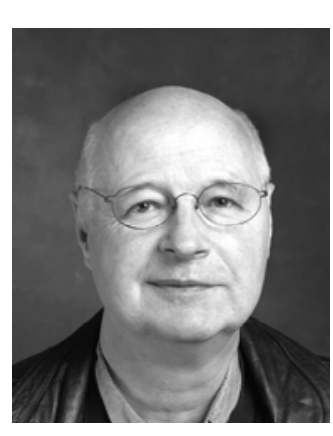

His employment experience includes the Danish Defense Research Council, Danish Ship Research Institute and Risoe National laboratory in addition to a 9 year period as self employed independent international wind energy consultant and 1 year as visiting professor at State University of New York, giving graduate and post graduate courses in wind turbine technology and application.

Per Lundsager has worked full time in wind energy since 1975 in areas including $R \& D$ and testing, system \& concept design and implementation, planning and feasibility studies. He has worked nationally and internationally for clients including private companies, public agencies and institutions, and international programmes, donors and agencies. Work experience includes national and international technology surveys and reviews, institution building and national/regional wind energy implementation plans, strategies and feasibility studies.

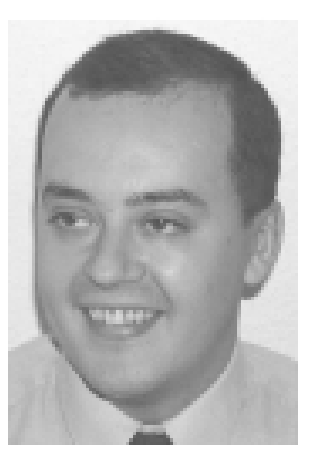

Vojtech Svoboda was born in Brno, Czech Republic, on April 23, 1973. He graduated with a Master of Electrical Engineering from the Brno University of Technology in 1996 at the Faculty of Electrical Engineering and Computer Science. He achieved Ph.D. degree at the same university in 2002 for his thesis 'The influence of fast charging on the performance of VRLA batteries'.

Since 1999 he has been working for the Centre of Solar Energy and Hydrogen Research in Ulm, Germany in the department of Electrochemical Accumulators. 